\title{
Characterization of the gene expression related to the process of DNA damage tolerance in Schistosoma mansoni
}

\author{
SH Silva, OS Pereira-Júnior, CS Silva*, OM Brigatto, E Macedo, V Rodrigues/ ${ }^{+}$
}

\author{
Departamento de Bioquímica e Imunologia, Faculdade de Medicina de Ribeirão Preto, Universidade de São Paulo, 14049-900 \\ Ribeirão Preto, SP, Brasil *Departamento de Microbiologia, Imunologia e Parasitologia, Instituto de Ciências Médicas, \\ Universidade Federal de Uberlândia, Uberlândia, MG, Brasil.
}

In the course of its complex life cycle, the parasite Schistosoma mansoni need to adapt to distinct environments, and consequently is exposed to various DNA damaging agents. The Schistosoma genome sequencing initiative has uncovered sequences from genes and transcripts related to the process of DNA damage tolerance as the enzymes $U B C 13, M M S 2$, and RAD6. In the present work, we evaluate the importance of this process in different stages of the life cycle of this parasite. The importance is evidenced by expression and phylogenetic profiles, which show the conservation of this pathway from protozoa to mammalians on evolution.

Key words: Schistosoma mansoni - ubiquitin conjugating enzymes - DNA damage tolerance

The trematode Schistosoma mansoni, the causative agent of schistosomiasis in Brazil, presents a complex life cycle, which alternates phases in vertebrate host, free life, and phases in invertebrate host. In order to complete this cycle, various morphologic and biochemical adaptations are important because different response is necessary to counteract the stimulus from a different environment. In attempt to answer some of these questions, a consortium was created to sequence the $S$. mansoni Transcriptome (Verjovski-Almeida et al. 2003) and this information has contributed to the understanding of the parasite biology.

DNA damage is one of the most common external interference in all-live organism, and the evolution generates diverse mechanisms to repair lesions on genome for the species conservation (Lindahl \& Wood 1999, Reddy \& Vasquez 2005). The mechanisms of tolerance to DNA lesions mediated by ubiquitination of the Proliferation Cell Nuclear Antigen (PCNA) were recently described to maintain the integrity of genetic material and viability of DNA replication (Hoege et al. 2002). Previous works show that Ubiquitin Conjugating Enzymes, such as RAD6, UBC13, and an E2 variant - MMS2, have an essential role in the control of mutagenic and non-mutagenic mechanisms of damage tolerance during DNA replication (Stelter \& Ulrich 2003). The enzyme RAD6 in a complex with the E3 RAD18 is responsible for the monoubiquitination of PCNA and recruitment of mutagenic polymerases in a process called Translesion Synthesis (Ulrich 2005). The E2 complex UBC13-MMS2 works with the E3 RAD5 to extend the poliubiquitin chain of the monoubiquitinated PCNA in a Lys-63 conformation to direct the error-free tolerance rep-

Financial support: CNPq, Fapesp, Capes ${ }^{+}$Corresponding author: vrodrigu@fmrp.usp.br

Received 25 May 2006

Accepted 26 June 2006 lication (Brown et al. 2002). The objective of this work is to analyze the expression of genes related to the tolerance control and estimate the importance of these pathways to Schistosome biology.

For the purpose of conduct experimental procedures, the putative sequences encoding to UBC13, MMS2, and RAD6 were obtained from data bank of Transcriptome Project (http://verjo18.iq.usp.br/schisto) to design primers to use in polymerase chain reaction (PCR) analysis. The Table shows the sequence of primers and the conditions used in PCR analysis for each gene. We extracted total RNA by Trizol (Invitrogen) method from the following stages: adult worm, eggs, germballs, cercaria, and schistosomula. A reverse transcription (RT-PCR) was performed using an oligo dT primer and a Thermoscript RTPCR system Kit (Invitrogen). We carried out the PCR using a Platinnum Taq DNA Polymerase Kit (Invitrogen) with the primers above described (Table). The sequence of PCR products was analized in the BlastX algoritm. The predicted amino acid sequence was used to generate a phylogenetic tree with the MEGA v. 3. program (www. megasoftware.net/mega3).

The sequences obtained from the Transcriptome Project, which encode for putative UBC13, MMS2, and RAD6 are the first evidence for the presence of damage tolerance pathways in this organism. Fig. 1 shows the results of the RT-PCR analysis, where the amplification of the transcripts was obtained in all stages of the parasite. The controls did not show innespecific amplification from DNA. These observations reflect the importance of this mechanism to keep the DNA integrity, since the exposition of the $S$. mansoni DNA to damaging agents may be constant during the life cycle. For example in the free life stages, the action of ultraviolet light and chemical pollutants and, in the other stages, the radicals of the host metabolism may be lethal for the parasite if it does not hold mechanisms to tolerate this lesions. The damage resultant from exposition of these agents may block the replication of DNA, and consequently inhibit cell division of the parasite. Repair mechanisms may cause negative effects because in the replication forks the regions of 
TABLE

Sequence of primers for reverse-transcription-polymerase chain reaction analyses

\begin{tabular}{|c|c|c|c|c|}
\hline Gene & Genbank & Primer sequence & $\begin{array}{l}\text { Annealing } \\
\text { temperature }\end{array}$ & $\begin{array}{c}\text { Expected } \\
\text { product (bp) }\end{array}$ \\
\hline SmUBC13 & DQ321733 & 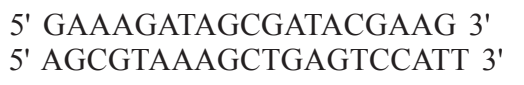 & $48^{\circ} \mathrm{C}$ & 319 \\
\hline SmMMS2 & DQ321734 & $\begin{array}{l}\text { 5' GATGAACTTGAGCAAGGACA 3' } \\
5^{\prime} \text { TGCAGACATTTTCTTGCGGA 3' }\end{array}$ & $45^{\circ} \mathrm{C}$ & 336 \\
\hline SmRAD6 & DQ321735 & $\begin{array}{l}\text { 5' ACTTCTGCGTGACTTGAAAC 3' } \\
5^{\prime} \text { TTCTTCGTACCAGCTTTCCT 3' }\end{array}$ & $48^{\circ} \mathrm{C}$ & 433 \\
\hline Sm $\alpha$-Tubulin & M80214 & $\begin{array}{l}\text { 5' CGCTCGCGGTCATTATAV 3' } \\
\text { 5' ATCCAGAACCGGTACCAC 3' }\end{array}$ & $47^{\circ} \mathrm{C}$ & 137 \\
\hline BgRPN1 & CV042523 & $\begin{array}{l}\text { 5' CCAGAGCTTCAGAAAGTTCT 3' } \\
5^{\prime} \text { AACTTGTCCTGCTAAATGCC 3' }\end{array}$ & $42^{\circ} \mathrm{C}$ & 456 \\
\hline
\end{tabular}

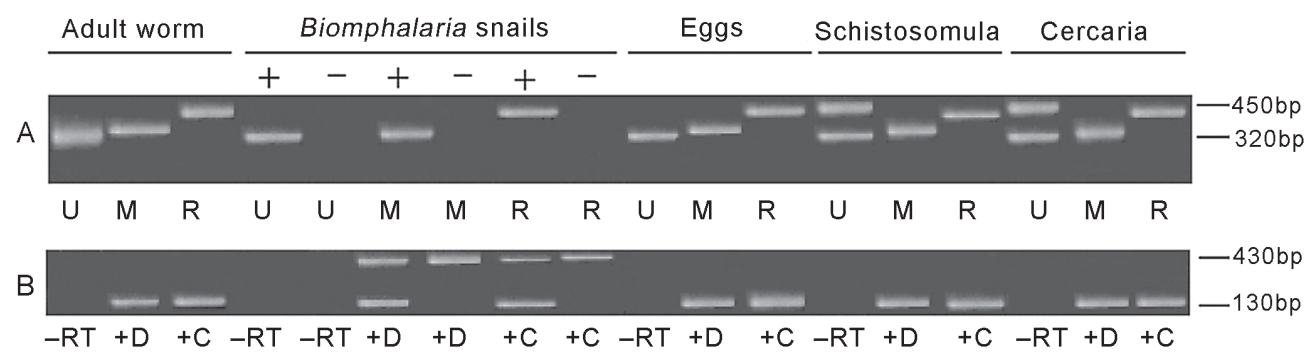

Fig. 1: detection of transcripts in adult worms, infected $(+)$ and non-infected $(-)$ Biomphalaria snails, eggs, cercaria, and schistosomula. A: reverse-transcription-polymerase chain reaction amplification of transcripts with the primers SmUBC13 (U), SmMMS2 (M), and SmRAD6 (R); B: control of amplification with Sm $\alpha$-Tubulin and of B. glabrata snails with BgRPN1 amplification. -RT: amplification of a RNA untreated with reverse transcripase; $+\mathrm{D}=\mathrm{RNA}$ previously treated with DNAse I; $+\mathrm{C}$ : positive control without treatment.

single stranded DNA are numerous. For this reason the cells bypass the damage and conclude replication to posterior repair, in a process called post-replication repair.

In human cells, other functions are described for the enzyme UBC13, like the control of the $\mathrm{G}_{1} / \mathrm{G}_{0}$ cell cycle checkpoint (Matsusaka \& Pines 2004) and activation of the IkB kinase (Deng et al. 2000). The latter may do not exist in schistosomes because of the absence of the Ubiquitin Conjugating Enzymes variant type 1 as observed in mammalians, which are responsible for the signaling. The enzyme RAD6 also presents distinct functions in a $\mathrm{N}$-end rule proteolysis and damage tolerance. For these reasons, the possibility of SmUBC13 and SmRAD6 to be acting in other pathways not may be excluded. To confirm the contribution to each pathway, additional works will be carried on.

The RT-PCR with total RNA of cercaria and schistosomula generated the amplification of two transcripts with SmUBC13: a 319 bp and a 450 bp products respectively. Both bands are eliminated in a PCR carried in high stringency conditions. Sequencing of these transcripts indicates the identity of SmUBC13 to the minor band and the major band corresponding to a non-previously described retrotransposon with similarity to Boudicca (Copeland et al. 2003). During the development of $S$. mansoni Transcriptome Project, several retrotransposons sequences were revealed, but the majority is expressed in all stages of the parasite life cycle as pseudogenes and does not convert to proteins. A retro-transposon differentially expressed consist in a possible regulation point of parasite metabolism in the stages of cercaria and schistosomula. Previous works have described the function of retroviral integrases in the regulation of the enzymes from tolerance pathways (Mulder et al. 2002). Additional works are necessary to characterize the functions of this transcript.

The phylogenetic relationship of the three enzymes focused on this work shows a similar organization, as showed in Fig. 2. The co-evolution of these genes is an evidence for the conservation of functions and preservation of an active DNA damage tolerance pathway. If the evolution of these genes were different, the interactions between the other would may be lost and these processes would turn to be inactive.

This work shows the partial characterization of some genes related to DNA damage tolerance in the parasite $S$. mansoni. The quantitative expression analysis of the repair and tolerance genes, and a biochemical characterization of these processes will be a next step to provide more specific information of the tolerance pathways in this parasite. 


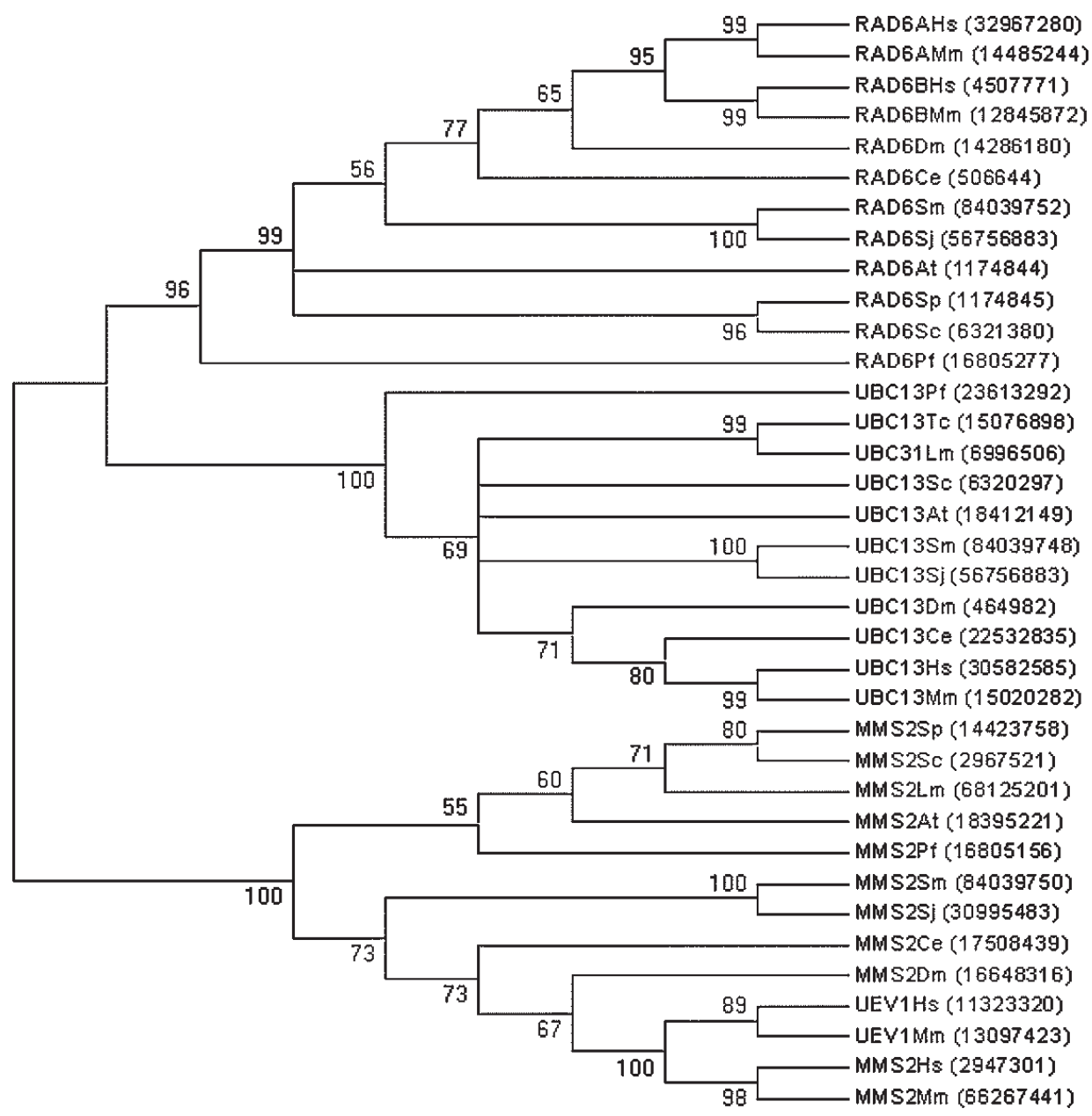

Fig. 2: phylogenetic analysis of entire amino acids sequence of UBC13, MMS2, and RAD6. The sequence is from Homo sapiens (Hs), Mus musculus (Mm), Schistosoma mansoni (Sm), S. japonicum $(\mathrm{Sj})$, Drosophila melanogaster (Dm), Plasmodium falciparum (Pf), Caenorhabiditis elegans (Ce), Arabidopsis thaliana (At), Schizosaccharomyces pombe (Sp), Saccharomyces cerevisiae (Sc), Trypanosoma cruzi $(\mathrm{Tc})$, and Leishmania major $(\mathrm{Lm})$. The bootstrap percentages are indicated above the branches.

\section{ACKNOWLEDGEMENTS}

To Dr William Castro Borges and Dr Renata Guerra-Sá for discussion and collaboration.

\section{REFERENCES}

Brown M, Zhu Y, Hemmingsen SM, Xiao W 2002. Structural and functional conservation of error-free DNA postreplication repair in Schizosaccharomyces pombe. DNA Repair 1: 869-880.

Copeland CS, Brindley PJ, Heyers O, Michael SF, Johnston DA, Williams DL, Ivens AC, Kalinna BH 2003. Boudicca, a retrovirus-like long terminal repeat retrotransposon from the genome of the human blood fluke Schistosoma mansoni. J Virol 77: 6153-6166.

Deng L, Wang C, Spencer E, Yang L, Braun A, You J, Slaughter C, Pickart C, Chen ZJ 2000. Activation of the IkappaB kinase complex by TRAF6 requires a dimeric ubiquitinconjugating enzyme complex and a unique polyubiquitin chain. Cell 103: 351-361.

Hoege C, Pfander B, Moldovan GL, Pyrowolakis G, Jentsch S
2002. RAD6-dependent DNA repair is linked to modification of PCNA by ubiquitin and SUMO. Nature 419: 135141.

Lindahl T, Wood RD 1999. Quality control by DNA repair. Science 286: 1897-1905.

Matsusaka T, Pines J 2004. Chfr acts with the p38 stress kinases to block entry to mitosis in mammalian cells. J Cell Biol 166: 507-516.

Mulder LC, Chakrabarti LA, Muesing MA 2002. Interaction of HIV-1 integrase with DNA repair protein hRad18. J Cell Biol 277: 27489-27493.

Reddy MC, Vasquez KM 2005. Repair of genome destabilizing lesions. Radiat Res 164: 345-356.

Stelter P, Ulrich HD 2003. Control of spontaneous and damage-induced mutagenesis by SUMO and ubiquitin conjugation. Nature 425: 188-191.

Ulrich HD 2005. The RAD6 pathway: control of DNA damage bypass and mutagenesis by ubiquitin and SUMO. Chembiochem 6: 1735-1743. 
Verjovski-Almeida S, Demarco R, Martins EA, Guimaraes PE, Ojopi EP, Paquola AC, Piazza JP, Nishiyama Jr. MY, Kitajima JP, Adamson RE, Ashton PD, Bonaldo MF, Coulson PS, Dillon GP, Farias LP, Gregorio SP, Ho PL, Leite RA, Malaquias LC, Marques RC, Miyasato PA, Nascimento, AL, Ohlweiler FP, Reis EM, Ribeiro MA, Sá
RG, Stukart GC, Soares MB, Gargioni C, Kawano T, Rodrigues V, Madeira AM, Wilson RA, Menck CF, Setubal JC, Leite LC, Dias-Neto E 2003. Transcriptome analysis of the acoelomate human parasite Schistosoma mansoni. Nat Genet 35: 148-157. 